\title{
A comparative study of the effect of amikacin administered through autoinjector and manual injection on biochemical parameters in rats
}

\author{
Anitha Roy ${ }^{1 *}$, R. Vijayaraghavan ${ }^{2}$, R. V. Geetha ${ }^{1}$, Anitha Magesh ${ }^{1}$, S. Vishnu Priya ${ }^{3}$, Anusha Ramasamy ${ }^{3}$, \\ U Vidyalakshimi $^{3}$, K RaagaNamrata ${ }^{3}$, S. Krishna Mohan ${ }^{3}$, Madhan Chakkaravarthy ${ }^{2}$ \\ ${ }^{1}$ Saveetha Dental College and Hospitals, ${ }^{2}$ Department of Research and Development, ${ }^{3}$ Saveetha Medical College and Hospital, Saveetha University, \\ Chennai - 600 072, Tamil Nadu, India.
}

\begin{tabular}{l} 
ARTICLE INFO \\
\hline Article history: \\
Received on: $08 / 09 / 2015$ \\
Revised on: $07 / 11 / 2015$ \\
Accepted on: $24 / 11 / 2015$ \\
Available online: $27 / 02 / 2016$ \\
\hline Key words: \\
Nephrotoxicity, creatinine, \\
urea, Amikacin, autoinjector, \\
biochemical parameters.
\end{tabular}

\begin{abstract}
Objective: The objective was to compare the biochemical changes of amikacin by autoinjector delivery and manual injection in rats.

Materials and Methods: Amikacin drug cartridge $(500 \mathrm{mg} / 2 \mathrm{~mL})$ for autoinjectors was diluted to $63 \mathrm{mg} / \mathrm{mL}$ and rats were administered $1.2 \mathrm{~mL}$, i.p. One group was given 3 and a second group 7 injection on consecutive days. 3 and 7 days manual injection of same dose of amikacin (about $500 \mathrm{mg} / \mathrm{kg}$, i.p.) and a control group (saline) were also included (total 5 groups). On day 4 or 8 biochemical parameters were studied.

Results: Significant increase in urea, creatinine and aspartate aminotransferase were observed in 7 days administration in both autoinjector and manual injection groups compared to control group. All other parameters viz., glucose, cholesterol, total triglycerides, bilirubin, uric acid, total protein, albumin, alanine aminotransferase and alkaline phosphatase did not show any significant change. No significant change was observed in 3 days administration groups.

Conclusion: High dose of amikacin for longer duration is known for its nephrotoxicity which is evidenced by the increase in urea and creatinine in both autoinjector and manual injection groups. This study shows that autoinjector device for amikacin which is new can be considered for further research work.
\end{abstract}

\section{INTRODUCTION}

Several developments have been made in drug formulations and delivery systems to meet the need of the patients as well as manufacturer (Zhou et al., 2014). Methods are available for self administration of the prescribed drugs for slow as well as rapid release of the drug. Administration of drugs by injection in emergency is mandatory and has many risks and challenges. In such a situation, use of autoinjector has many benefits. Autoinjector devices are developed for rapid selfadministration of the recommended drugs. In the autoinjector the drugs are delivered by deep intramuscular injection with a spray effect, resulting in increased area and faster drug absorption. The needle is not visible in the autoinjectors which can reduce anxiety and needle phobia. These devices are well suited for mass casualty situations and will be painless and convenient. Autoinjector devices are available only for a few emergency situations (Vijayaraghavan, 2012). Autoinjector devices of

\footnotetext{
* Corresponding Author

Email: anitharoypeeter@yahoo.co.in
}

atropine sulphate and pralidoxime chloride are available for nerve agent exposure in war scenarios (Vijayaraghavan et al., 2012; Vijayaraghavan et al., 2007). Only for a few emergency situations the recommended drugs are available as autoinjectors viz., midazolam for seizures, diazepam for status epilepticus, epinephrine for anaphylaxis and sumatriptan for migraine (Lamson et al., 2011; Sicherer et al., 2007; Levy et al.,2004; Monstad et al., 1995).

Recent times have witnessed several natural (earth quake, flood, avalanche, tsunami) and manmade (military operations, terrorism, rail and road accidents) disasters in which the medical attention could not reach in desired time (Yamanouchi et al., 2014). Any delay in medical attention in critical situations with serious injury may end up in severe infection. In such conditions autoinjector of an antibacterial drug will be highly useful. Several reports are available that preventing the infection in the initial stage significantly reduces morbidity and mortality (Rodriguez et al., 2014; Gillespie and Walenkamp, 2010).

The emergence of bacterial resistance to commonly used antibiotics has necessitated retention of the aminoglycosides as a viable treatment option. 
Aminoglycosides are an attractive treatment alternative due to their chemical stability, fast bactericidal effect, synergy with $\beta$--lactam antibiotics, low incidence of resistance, and relative lower cost. (Wargo and Edwards, 2014) They show post antibiotic effect and are not metabolized in the body and normally excreted as such in the urine.

Aminoglycosides bind mainly to 30 s ribosomes and interfere with initiation of protein synthesis, block the translation of mRNA and prematurely terminate the protein synthesis. Incorrect amino acids are incorporated in the protein chain leading to abnormal protein production in the microorganism.

Amikacin is a broad spectrum amino glycoside antibiotic derived from kanamycetin and is highly effective against gram negative organisms (including gentamycin resistant strains) as well as few gram positive organism (Cunha, 1988).

The amikacin autoinjector is a new device and was developed as a reusable autoinjector in which the drug cartridges can be changed and can deliver full dose or partial dose (Vijayaraghavan et al., 2014). The advantage of amikacin is its safety and can be supplemented with other antibiotics when medical attention arrives The purpose of the study was to compare the usability and tolerability of Amikacin administered through autoinjectors with manual injection using haematological and biochemical parameters in rats.

\section{MATERIALS AND METHODS}

\section{Drugs and chemicals}

Amikacin drug cartridge developed by Saveetha University with the collaboration of Defence Research and Development Organization and M/s Neon Laboratories (Mumbai), was used for the study.

This autoinjector has the option to select full dose delivery or partial dose delivery (dual dose autoinjector). The cartridge was made for human dosage (500 $\mathrm{mg}$ in $2 \mathrm{~mL}$ ) of amikacin as amikacin sulphate with stabilizers. The cartridge was made with 2.3 to $2.4 \mathrm{~mL}$ of drug solution and upon ejection by the autoinjector $2.1 \mathrm{~mL}$ to $2.2 \mathrm{~mL}$ would be delivered. The other chemicals were either Indian Pharmacopoeia grade or analytical grade purchased from standard companies.

\section{Animals}

Female Wistar rats weighing 120 - $180 \mathrm{~g}$ were used from Biomedical Research Unit and Laboratory Animal Centre (BRULAC, Saveetha University). Rats were fed with a standard commercial pellet diet from TANUVAS (Chennai) and drinking water ad libitum.

Animals were maintained during the whole experimental period in accordance with the guidelines of 'Committee for the Purpose of Control and Supervision of Experiments on Animals' (CPCSEA, India). The rats were maintained at $25 \pm 2{ }^{\circ} \mathrm{C}, 40$ to 60 $\%$ relative humidity and natural dark/light cycle. The study was approved by Institutional Animal Ethical Committee of Saveetha University (SU/ BRULAC/RD/010/2014, Dated, 30 May 2014).

\section{Dilution of drug cartridge}

The experiment was designed to administer higher dose of amikacin for a shorter and a longer duration. The human dose cartridge was diluted 1:4. For this, $1.75 \mathrm{~mL}$ of the drug solution was withdrawn from the cartridge under a laminar flow and 1.75 $\mathrm{mL}$ of sterile saline was injected back to make the concentration to $63 \mathrm{mg} / \mathrm{mL}$. The drug cartridge was loaded in the autoinjector with the plastic clip restrictor (Fig 1) so as to deliver partial volume of the cartridge (about $1.2 \mathrm{~mL}$ against $2.4 \mathrm{~mL}$ ). This also would allow only a portion of the needle to be ejected (about1.5 $\mathrm{cm}$ against $2.5 \mathrm{~cm}$ ). For a rat of $150 \mathrm{~g}$ the delivered dose would be about $500 \mathrm{mg}(63 \times 1.2 \times 1000 / 150)$. When the clip is removed the autoinjector will deliver full dose with full needle out. The refilled amikacin cartridges were subjected to various quality control parameters viz, ruggedness test, firing efficacy test, stability test, low pressure test and vibration test (Vijayraghavan et al., 2007)

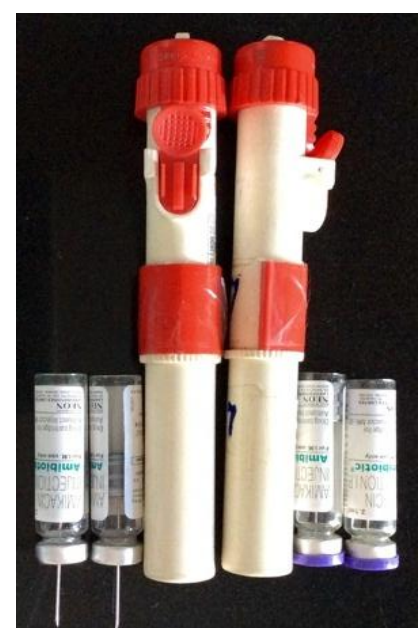

Fig. 1: Amikacin drug cartridge and reusable autoinjector with restrictor delivering partial dose with partial needle out.

\section{Experimental groups}

Thirty five female rats were randomly allocated to the following groups (7 rats per group).

Group 1: Control,

Group 2: Amikacin injection, $63 \mathrm{mg} / \mathrm{mL}$ (1.2 mL) i.p for 3 days by autoinjector,

Group 3: Amikacin injection, $63 \mathrm{mg} / \mathrm{mL}$ (1.2 mL) i.p. for 3 days by manual injection.

Group 4: Amikacin injection, $63 \mathrm{mg} / \mathrm{mL}$ (1.2 mL) i.p for 7 days by autoinjector

Group 5: Amikacin injection, $63 \mathrm{mg} / \mathrm{mL}(1.2 \mathrm{~mL})$ i.p. for 7 days by manual injection.

The rats were held firmly on the surgical table with its back on the table. The autoinjector was unlocked and positioned gently on the lower abdomen vertically. The trigger button was pressed and held on to the abdomen for 10 seconds. The autoinjector was then removed gently and the needle length that was protruding from the cartridge was measured. The drug cartridge was weighed before and after injection to estimate the 
quantity of the drug injected. For the manual injection the drug solution removed from the cartridge was diluted suitably with sterile normal saline to get a concentration of $63 \mathrm{mg} / \mathrm{mL}$ and from this $1.2 \mathrm{~mL}$ was injected intra- peritoneally (i.p.) for each rat.

\section{Sample collection}

The animals were weighed daily. General behavior, food and water intake were recorded. Twenty four hours after the last dose $\left(4^{\text {th }}\right.$ or $8^{\text {th }}$ day) animals were anaesthetized with isoflurane and blood was collected from the orbital sinus in two separate tubes, one with anticoagulant (EDTA) and the other without anticoagulant. After the collection of the blood the animals were sacrificed with over dose of anesthesia. Then organs like heart, lungs, spleen, kidney and liver were excised, blotted free of blood, weighed and preserved in formalin solution.

\section{Biochemical parameters}

From the tubes without anticoagulant serum was separated from control and experimental groups. The serum was used for the estimation of glucose, cholesterol, total triglycerides (TGL), bilirubin, urea, creatinine, uric acid, total protein, albumin, aspartate aminotransferase (AST), alanine aminotransferase (ALT) and alkaline phosphatase (ALP). Roche's standard kits were used for the analysis as per the manufacturer's instruction using Modular P100 Autoanalyser. Glucose was estimated by ortho toluedene method (Dubowski, 1962). Trinder's method was adopted for the estimation of cholesterol and triglycerides (Trinder, 1969). Urease and uricase method of Trinder was used for the estimation of urea and uric acid respectively (Prencipe et al., 1978; Yanagi., 1924). Creatinine was estimated by Jaffe's method (Husdan and Rapoport, 1968). AST, ALT and ALP were estimated by IFCC method (Lustig et al., 1988). Biuret method was adopted for total protein (Wokes and Still, 1942), dye binding protein method for albumin (Robertson, 1981) and Diazo method for total bilirubin (Rand and Pasqua, 1961).

\section{Statistical analysis}

All the parameters were analysed using one way analysis of variance (ANOVA) and compared with control using Dunnett's test. A probability of 0.05 and less was taken as statistically significant. The analysis and plotting of graphs were carried out using SigmaPlot 12 (Systat Software Inc., USA).

\section{RESULTS}

The refilled amikacin drug cartridges complied with all the quality control parameters. Depending upon the dilution and use the dose delivered through the autoinjector varies. In the present study the dose administered to the rats by i.p. is $484.9 \pm$ $83.7 \mathrm{mg} / \mathrm{kg}$ (mean $\pm \mathrm{SD}, \mathrm{n}=60$ ). The i.p. administration of amikacin by autoinjector in the rats was quick and easy. The rats apparently did not show pain or bleeding due to autoinjector delivery. The general behavior, food consumption, water intake and body weight of the rats did not show any significant difference among the groups.

There was no significant change in the levels of serum glucose, cholesterol, TGL and bilirubin in 3 day and 7 day groups of autoinjector and manual injection compared to control group (Fig 2). No significant change was observed in the levels of serum total protein and albumin in 3 day and 7 day groups of autoinjector and manual injection compared to control group (Table 1).

Table 1: Effect of amikacin administered through autoinjector and manual injection by i.p. on Serum total protein and albumin in rats.

\begin{tabular}{llll}
\hline Group & N & $\begin{array}{l}\text { Protein } \\
\text { (units) }\end{array}$ & $\begin{array}{l}\text { Albumin } \\
\text { (units) }\end{array}$ \\
\hline Control & 7 & $6.61 \pm 0.09$ & $3.70 \pm 0.05$ \\
Autoinjector -3 doses & 7 & $6.60 \pm 0.14$ & $3.81 \pm 0.08$ \\
Manual injection-3 doses & 7 & $6.78 \pm 0.10$ & $3.87 \pm 0.09$ \\
Autoinjector -7 doses & 7 & $6.67 \pm 0.15$ & $3.60 \pm 0.10$ \\
Manual injection -7 doses & 4 & $6.37 \pm 0.26$ & $3.85 \pm 0.06$ \\
F & & 0.954 & 1.982 \\
P & & NS & NS \\
\hline
\end{tabular}

Mean $\pm S E ; n=7$ for all, except manual 7 doses $n=4$.

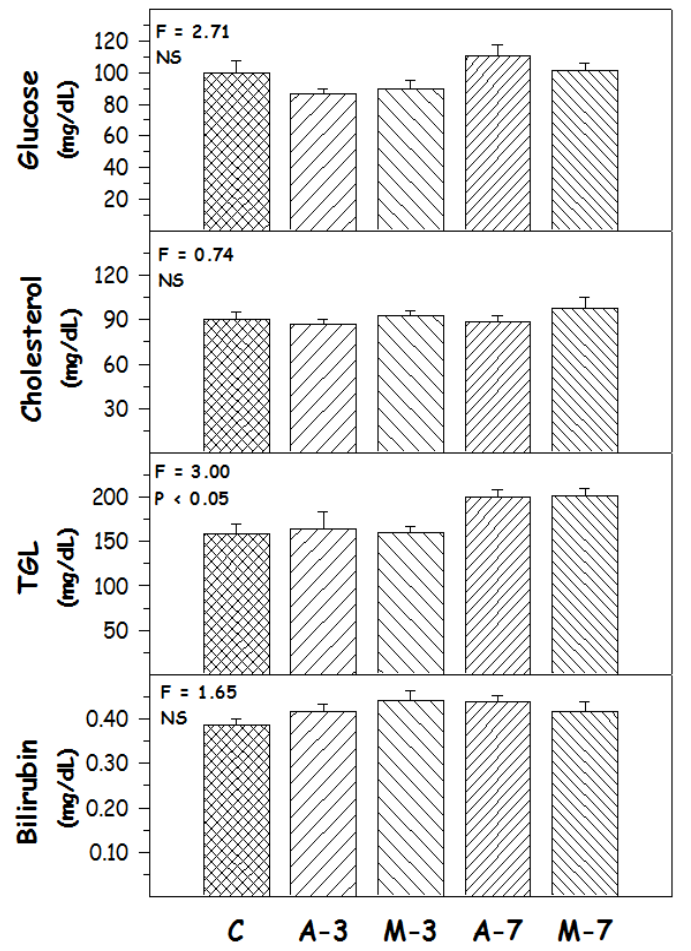

Fig 2: Effect of amikacin administered through autoinjector and manual injection by i.p. on serum glucose, cholesterol, TGL and bilirubin in rats. $\mathrm{C}=$ Control Group; A-3 = Autoinjector 3 doses; M-3 = Manual Injection 3 doses; A-7 = Autoinjector 7 doses; M-7 = Manual Injection 7 doses; Mean \pm SE; $n=7$ for all, except Manual 7 doses $n=4$. One Way ANOVA followed by Dunnett's comparison test with Control Group.* statistically significant from Control Group.

Administration of amikacin for 3 days by autoinjector and manual injection did not show any significant change in the activities of the three enzymes studied i.e., AST, ALT and ALP. But, 7 day administration of amikacin by autoinjector and by manual injection significantly increased the AST activity and not of ALT and ALP (Fig 3). 


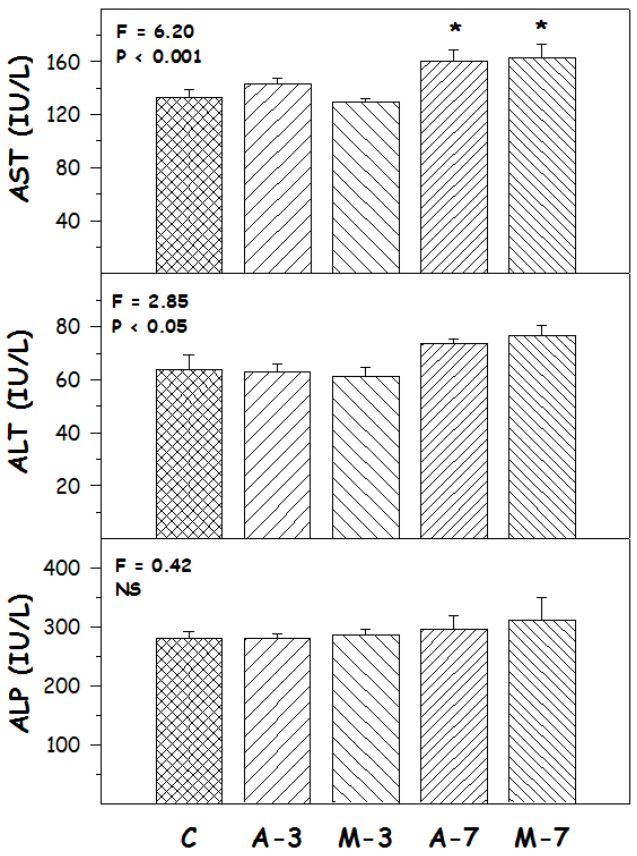

Fig 3: Effect of amikacin administered through autoinjector and manual injection by i.p. o the activities of serum AST, ALT and ALP in rats. C = Control Group; A-3 = Autoinjector 3 doses; M-3 = Manual Injection 3 doses; A-7 = Autoinjector 7 doses; M-7 = Manual Injection 7 doses; Mean \pm SE; $n=7$ for all, except Manual 7 doses $n=4$. One Way ANOVA followed by Dunnett's comparison test with Control Group. * Statistically significant from Control Group.

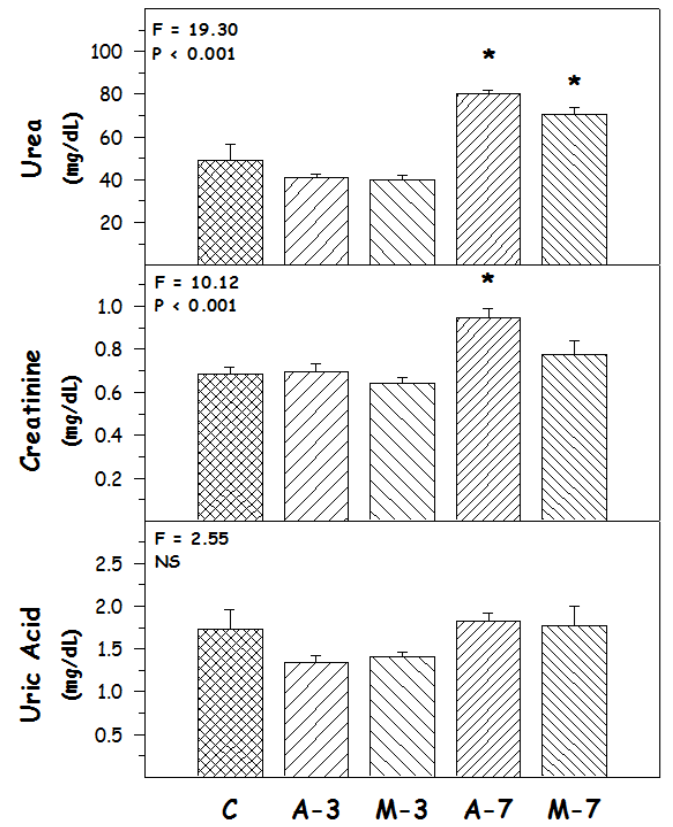

Fig. 4: Effect of amikacin administered through autoinjector and manual injection by i.p.on serum urea, creatinine and uric acid in rats. $\mathrm{C}=\mathrm{Control}$ Group; A-3 = Autoinjector 3 doses; M-3 = Manual Injection 3 doses; A-7 = Autoinjector 7 doses; M-7 = Manual Injection 7 doses; Mean \pm SE; $n=7$ for all, except Manual 7 doses $n=4$.One Way ANOVA followed by Dunnett's comparison test with Control Group. * Statistically significant from Control Group.

Similarly, 3 days administration of amikacin by autoinjector and manual injection did not show any significant change in the levels of urea, creatinine and uric acid. But, 7 day administration of amikacin by autoinjector and by manual injection increased the levels of urea and creatinine, and the increase in autoinjector group is statistically significant. There was no change in the level of uric acid (Fig 4).

\section{DISCUSSION}

Thousands of mass disasters have occurred throughout the world (IFRC, 2013). In the last three decades more than 100 earth quakes and about 1000 cyclones have occurred, causing more than 2 million deaths. Over 100 million people have been seriously injured causing pain and infection. Other than natural disasters, manmade terrorism also cause mass disasters like the one on World Trade Centre in USA (Jordon et al., 2011). These disasters affect the environmental condition and stimulate pathogenic organisms that are endemic and dormant in nature (Keven et al., 2003). Coupled with the disaster crisis the infectious diseases cause morbidity causing serious economic burden to the affected areas.

It is absolutely essential to mobilize medical assistance immediately during natural and manmade disasters. Due to the disruption of the support systems the conventional medical assistance largely gets disturbed. The relief efforts become inappropriate resulting in increased mortality and morbidity. Infections due to wounds and injuries, contaminated food and water, and vector borne diseases are the causes of communicable diseases in disaster situations (Jafari et al., 2011). With appropriate intervention with medication, high morbidity and mortality resulting from communicable diseases can be avoided to a great extent. Medical treatment by trained personal may be difficult in such type of situations due poor access. Before the full medical assistance arrives, if pain and infection can be taken care in the field conditions, the suffering of the injured people can be reduced. Autoinjectors with an analgesic drug and an antibacterial drug with pre-filled drug cartridges will be very useful as they can be used by simple instruction printed on the device (Vijayaraghavan et al., 2012). In most of the disaster situations the gram negative organisms are responsible for infection (Kang et al., 2009). Amikacin is a broad spectrum aminoglycoside antibiotic used for gram negative infections by parenteral route. Many severe infections with Pseudomonas aeruginosa, Enterobacter, Klebsiella, Serratia and other gram-negative bacteria resistant to other antibiotics are treated with amikacin (Saavedra et al., 1986). Amikacin is most commonly used for septicemia, bacterial endocarditis, peritonitis, meningitis, pelvic inflammatory disease and pneumonia. Aminoglycosides are continuously being used in clinical practice because of their bactericidal efficacy, synergism with B-lactam agents, low cost, limited bacterial resistance, and a post-antibiotic effect (Gonzalez and Spencer, 1998; Cunha, 1988).

The autoinjector delivers the drug by deep intramuscular injection with a force covering large area for a quick absorption. Hence the tolerance and acceptability of the autoinjector delivered amikacin compared with manual injection in animal model was studied to progress further for human clinical use. Rat model with 
intraperitoneal route was selected in the present study, so that if it is tolerable, larger animals with other routes like i.v and i.m will be more acceptable. Biochemical parameters can act as indicators for various body functioning. Aminoglycosides are known for its nephrotoxicity, ototoxicity and neuromuscular blocking activity (Peloquin et al., 2004). Hence, in this study, the various biochemical parameters were studied, as alterations in these parameters have clinical significance. Organ to body weight ratio did not show any significant difference except kidney (data not shown). Biochemical parameters especially serum AST, ALT and ALP are the most sensitive markers employed in the diagnosis of hepatic damage (Ezhilarasan et al., 2012). The present study showed that the effects of amikacin by autoinjector delivery and manual injection are same. Amikacin and other aminoglycosides do not cause hepatotoxicity (Mor et al., 1990). In the present study high dose of amikacin by autoinjector delivery and manual injection did not change the alanine aminotransaminases. A significant increase in AST, urea and creatinine were observed in 7 day administration in both autoinjector delivery and manual injection showing that at high dose and longer duration nephrotoxicity can occur. The effects are comparable in autoinjector delivery and manual injection. All other parameters viz., glucose, cholesterol, total triglycerides, bilirubin, uric acid, total protein and albumin did not show any significant change in both the methods of drug delivery. The intention of amikacin autoinjector is to protect the patients from complications of wound infection and communicable diseases in disaster situations till they get actual medical attention. In the disaster situations amikacin autoinjector device can also be considered for farm and pet animals.

\section{CONCLUSION}

Aminoglycosides are known for its dose dependent nephrotoxicity, which is evidenced by the changes in the biochemical parameters when it is administered consecutively for 7 days by autoinjector as well as manual injection. No additional effect was observed in the autoinjector group showing its safety and easy usage. As there is no antibiotic autoinjector available, amikacin autoinjector device can be considered for future research for mass casualty management.

\section{ACKNOWLEDGEMENTS}

The authors are thankful to Dr. E. Sukumar for his valuable indent suggestions.

\section{COMPETING INTERESTS}

The authors declared no potential conflicts of interest

\section{REFERENCES}

Cunha BA. Aminoglycosides: current role in antimicrobial therapy. Pharmacotherapy, 1988; 8:334-350.

Dubowski KM. An O-toluidine method for body-fluid glucose determination. Clin Chem, 1962; 8:215-235.
Ezhilarasan D, Karthikeyan S, Vivekanandan P. Ameliorative effect of silibinin against N-nitrosodimethylamine-induced hepatic fibrosis in rats. Environ Toxicol Pharmacol, 2012; 34:1004-13.

Gillespie WJ, Walenkamp GH. Antibiotic prophylaxis for surgery for proximal femoral and other closed long bone fractures. Cochrane Database Syst Rev, 2010; 217:CD000244.

Gonzalez LS, Spencer JP. Aminoglycosides: a practical review. Am. Fam. Physician, 1998; 58:1811-1820.

Husdan H, Rapoport A. Estimation of creatinine by the Jaffe reaction. A comparison of three methods. Clin Chem, 1968; 14:222 238

IFRC. 2013. International Federation of Red Cross and Red Crescent Societies, World Disasters Report 2013; Focus on technology and the future of humanitarian action. Switzerland.pp. 283.

Jafari N, Shahsanai A, Memarzadeh M, Loghmani A. Prevention of communicable diseases after disaster: A review, J Res Med Sci, 2011; 16:956-962.

Jordan HT, Brackbill RM, Cone JE, Debchoudhury I, Farfel MR, Greene CM, Hadler JL, Kennedy J, Li J, Liff J, Stayner L, Stellman SD. Mortality among survivors of the Sept 11, 2001, World Trade Center disaster: results from the World Trade Center Health Registry cohort. Lancet, 2011; 378:879-887.

Kang M, Xie Y, Mintao C, Chen Z, Chen H, Fan H, Chen W, Guo Antimicrobial susceptibility of clinical isolates from earthquake victims in Wenchuan. Clin Microbiol Infect, 2009; 15: 87-92.

Keven K, Ates K, Sever MS, Yenicesu M, Canbakan B, Arinsoy T, Ozdemir N, Duranay M, Altun B, Erek E.Infectious complications after mass disasters: the Marmara earthquake experience, Scand J Infect Dis, 2003; 35:110-113.

Kurt A. Wargo and Jonathan D. Edwards AminoglycosideInduced Nephrotoxicity, Journal of Pharmacy Practice, 2014; 27:573-577

Lamson MJ, Sitki-Green D, Wannarka GL, Mesa M, Andrews P, Pellock J., Pharmacokinetics of diazepam administered intramuscularly by autoinjector versus rectal gel in healthy subjects: a phase I, randomized, open-label, single-dose, crossover, single-centre study. Clin. Drug Investig, 2011; 31:585 - 597.

Levy A, Kushnir M, Chapman S, Brandeis R, Teitelbaum Z, Gilat E. Characterization of early plasma concentrations of Midazolam in pigs after administration by an autoinjector. Biopharm. Drug Dispos, 2004; $25: 297$ - 301.

Lustig V, Papanastasiou-Diamandis A, Goldberg DM. Evaluation of commercially formulated aspartate aminotransferase and alanine aminotransferase activity determinations by the Scandinavian Committee on Enzymes and IFCC methods as modified for use with automated enzyme analysers. Clin Biochem, 1988; 21:283-290.

Monstad I, Krabbe A, Micieli G, Prusinski A, Cole J, Pilgrim A, Shevlin P., Preemptive oral treatment with sumatriptan during a cluster period. Headache, 1995; 35:607 - 613.

Mor F, Leibovici L, Cohen O, Wysenbeek AJ.Prospective evaluation of liver function tests in patients treated with aminoglycosides. DICP, 1990; 24:135-137.

Peloquin CA, Berning SE, Nitta AT, Simone PM, Goble M, Huitt GA, Iseman MD, Cook JL, Curran-Everett D. Aminoglycoside toxicity: daily versus thrice-weekly dosing for treatment of mycobacterial diseases. Clin Infect Dis, 2004; 38: 1538-1544.

Prencipe L, Fossati P, Vanzetti G.Enzymatic determination of uric acid in serum with the Trinder reaction. Quad Sclavo Diagn, 1978; 15: 382-394.

Rand RN and Pasqua AD.A new Diazo method for the determination of bilirubin. Clin Chemistry, 1962; 8: 570- 578

Robertson WS.Optimizing determination of plasma albumin by the bromcresol green dye-binding method. Clin Chem, 1981; 27:144-146

Rodriguez L, Jung HS, Goulet JA, Cicalo A, Machado-Aranda DA, and Napolitano LM. Evidence-based protocol for prophylactic antibiotics in open fractures: improved antibiotic stewardship with no increase in infection rates. J Trauma Acute Care Surg, 2014; 77:400-408.

Saavedra S, Vera D, Ramírez-Ronda CH. Susceptibility of aerobic gram-negative bacilli to aminoglycosides. Effects of 45 months of 
amikacin as first-line aminoglycoside therapy. Am J Med, 1986; 80; 6570 .

Sicherer SH, Simons FE. Section on Allergy and Immunology, American Academy of Pediatrics.Self-injectable epinephrine for first-aid management of anaphylaxis. Pediatrics, 2007; 119: 638 - 646.

Trinder P. Triglyceride estimation by GPD-PAP method. Ann Clin Biochem, 1969; 6:24 -27.

Vijayaraghavan R, Bhaskar ASB, Gautam A, Gopalan N,Singh AK,Beer Singh ,Flora SJS,.A. convenient first aid kit for chemical and biological agents and radiation exposure. J Environ Biol, 2012; 33:673681.

Vijayaraghavan R, Jain N, Gautam A, Sharma M, Singh S, Kumar D, Singh R, Kumar P, Gupta AK, Jain S. Evaluation of the antidotal efficacy of atropine sulphate and pralidoxime chloride given by autoinjectors against nerve agent (sarin) toxicity. Med. C.B.R. Def, 2007; $5: 1-12$.

Vijayaraghavan R, Selvaraj R, Krishna Mohan S, Gopi PG, Tharani.Haematological and Biochemical Changes in Response to Stress Induced by the Administration of Amikacin Injection by Autoinjector in Animals. Def Sci J, 2014; 64:99-105.

Vijayaraghavan R. Autoinjector device for rapid administration of life saving drugs in emergency. Def. Sci. J, 2012; 62: 307 - 314
Wokes $\mathrm{F}$ and Still BM.Estimation of protein by the Biuret and Greenberg methods. Biochem J, 1942, 36: 797 - 806.

Yamanouchi S, Ishii T, Molino K, Furukawa H, Hozawa A, Ochi S, Kushimoto S. Streamlining of medical relief to areas affected by the Great East Japan earthquake with the "area-based/line-linking support system". Prehosp Disaster Med, 2014; 29: 614-622.

Yanagi K. A New calorimetric method for determination of urea with urease - a comparative study.J Am Med Asso, 1924; 82 1169- 1171.

Zhou QT, Tang P, Leung SS, Chan JG, Chan HK.Emerging inhalation aerosol devices and strategies: where are we headed? Adv Drug Deliv Rev. 2014; 75:3-17.

\section{How to cite this article:}

Anitha R, Vijayaraghavan R, Geetha RV, Anitha M, Vishnu Priya S, Anusha R, Vidyalakshimi U, RaagaNamrata K, Krishna Mohan S, Chakkaravarthy M. A comparative study of the effect of amikacin administered through autoinjector and manual injection on biochemical parameters in rats. J App Pharm Sci, 2016; 6 (02): 109-114. 